\title{
Does learning a language in the elderly enhance switching ability?
}

Article in Journal of Neurolinguistics · January 2017

DOI: 10.1016/j.jneuroling.2016.09.001

CITATION

1

5 authors, including:

\section{Eneko Antón}

Basque Center on Cognition, Brain and Lang. . 7 PUBLICATIONS 180 CITATIONS SEE PROFILE

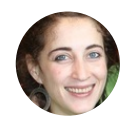

Aina Casaponsa

Lancaster University

7 PUBLICATIONS 20 CITATIONS

SEE PROFILE

\section{Jon Andoni Duñabeitia}

Basque Center on Cognition, Brain and Lang...

95 PUBLICATIONS 1,677 CITATIONS

SEE PROFILE

Some of the authors of this publication are also working on these related projects:

Project Phonological and orthographic coding in skilled deaf readers View project 
Does learning a language in the elderly enhance switching ability?

\author{
Sara Ramos ${ }^{1,2 *}$ \\ Yuriem Fernández García ${ }^{2 *}$ \\ Eneko Antón ${ }^{2}$ \\ Aina Casaponsa ${ }^{2,3}$ \\ and \\ Jon Andoni Duñabeitia ${ }^{2}$
}

${ }^{1}$ Language Acquisition and Language Processing Lab, Department of Language and Literature,

Norwegian University of Science and Technology; Trondheim, Norway.

${ }^{2}$ Basque Center on Cognition, Brain and Language (BCBL); Donostia, Spain.

${ }^{3}$ Department of Linguistics and English Language, Lancaster University; Lancaster, United Kingdom.

\title{
Contact information:
}

Jon Andoni Duñabeitia

Basque Center on Cognition, Brain and Language

Paseo Mikeletegi 69, $2^{\text {nd }}$ floor

20009 Donostia

+34943309300 (ext. 208)

j.dunabeitia@bcbl.eu

* The two first authors contributed equally to this manuscript. 


\begin{abstract}
The bilingual advantage has been subject of research repeatedly over the last decade. Many studies have supported the idea of the existence of a higher functioning in domain general cognitive abilities among bilingual samples as compared to monolingual samples. However, this idea has been recently challenged by a number of scholars, and a recent body of evidence suggests that the acquisition of a new language does not necessarily involve an enhancement of domain-general non-linguistic abilities. In the current study we aimed at exploring the relationship between language learning and switching ability in elderly monolingual participants who learned a second language during a whole academic year. A colour-shape switching task was used as a measure of switching ability and was administered twice in a pre-test/post-test design, both to the critical group of seniors attending a languagelearning course on a regular basis and to a group of age-matched monolingual seniors who did not attend to any language-learning course and that served as controls. Results showed that switching costs in the post-test were not significantly different from those in the pre-test in either the experimental or the control groups, demonstrating that the acquisition of a second language in the elderly does not necessarily lead to an enhancement of switching ability as measured by switching costs. We acknowledge the need of further longitudinal L2 training studies to reach clear conclusions on the effects of language learning in domaingeneral executive control.
\end{abstract}

Keywords: Switching; Cognitive Reserve; Bilingualism; Second Language Acquisition; Language Learning; Bilingual Advantage; Cognitive Flexibility. 


\section{INTRODUCTION}

The so-called bilingual advantage hypothesis suggests that bilingualism may lead to an improvement in domain-general executive control abilities as compared to monolinguals. Updating, switching and inhibition are components of this not unitary construct known as executive functions (EF) (Miyake \& Friedman, 2012), and bilingualism has been often linked with a specific enhancement of these components, suggesting that bilinguals outperform monolinguals in monitoring (as the ability to update the information in the working memory), in shifting (as the ability to switch between tasks), and/or in inhibition (as the ability to suppress dominant responses). Due to the fact that using two languages on a daily basis requires updating the information of the relevant language depending on the context, shifting from one language to another and suppressing the non-relevant language, it has been hypothesized that bilingualism could have an impact on domain-general executive functions.

In the last decade a surge of studies have confirmed the effects of bilingualism on domain-general cognitive functions using several non-linguistic executive control tasks in different age populations (e.g., Barac \& Bialystok, 2012; Bialystok, Craik, \& Luk, 2008; Bialystok, Craik, Klein, \& Viswanathan, 2004; Bialystok, Craik, \& Luk, 2012; Gold, Kim, Johnson, Kryscio, \& Smith, 2013; Hernandez, Costa, Fuentes, Vivas, \& Sebastian-Galles, 2010; Kroll \& Bialystok, 2013). There is also research showing that lifelong bilingualism attenuates age-related cognitive control decline (Bak, Nissan, Allerhand, \& Deary, 2014; 
Bialystok \& Craik, 2010; Wilson, Boyle, Yang, James, \& Bennett, 2015), and that bilingualism contributes to cognitive reserve in aging populations including a delay in the onset of dementia symptoms (see Bialystok, Abutalebi, Bak, Burke, \& Kroll, 2016, for review).

However, a whole body of evidence against this so-called bilingual advantage at the behavioral and neural level has emerged recently, arguing that these differential effects do not exist, or that they are restricted to specific undetermined circumstances (Antón et al., 2014; Antón, Fernández García, Carreiras, \& Duñabeitia, 2016; de Bruin, Bak, \& Della Sala, 2015; Duñabeitia et al., 2014; Gathercole et al., 2014; Paap \& Greenberg, 2013; Paap, Johnson, \& Sawi, 2015; Paap, Johnson, \& Sawi, 2016). Also, several longitudinal studies following individuals that had no signs of dementia at the initial test moment have reported nonsignificant results in the delay of the emergence of dementia-related symptomatology related to bilingualism (Crane et al., 2010; Lawton, Gasquoine, \& Weimer, 2015; Sanders, Hall, Katz, \& Lipton, 2012; Zahodne, Schofield, Farrell, Stern, \& Manly, 2014), thus questioning the validity of the so-called bilingual advantage.

Together, the studies mentioned above studying differences between bilinguals and monolinguals in different age populations and the relationship between lifelong bilingualism and cognitive reserve in older populations have used tasks that require active processing of incongruent or salient irrelevant information. Among the paradigms that have been mainly used in order to investigate the set of executive control abilities (monitoring, switching and inhibition) the most commonly used ones are the Simon task (Simon \& Rudell, 1967), the flanker task (Eriksen \& Eriksen, 1974), the Stroop task (Stroop, 1935), and several forms of switching tasks (see Rubin \& Meiran, 2005; see also Prior \& MacWhinney, 2010). The evidence from these tasks in the bilingual domain stems from different behavioral and electrophysiological studies, and interestingly, several versions of all these tasks using 
linguistic and non-linguistic stimuli have been used in fMRI designs to study the relationship between brain activation and the specific conditions of interest (e.g., the switch trials in a switching paradigm; see Luk, Green, Abutalebi, \& Grady, 2011; see also Pliatsikas \& Luk, 2016, for a review). Nevertheless, the finding of a difference at the level of brain activity does not necessarily imply a bilingual advantage, nor does the existence of relatively inconsistent structural evidence in favor of an anatomical difference between bilinguals and monolinguals at the neural level (see García-Pentón, Fernández García, Costello, Duñabeitia, \& Carreiras, 2016a; García-Pentón, Fernández García, Costello, Duñabeitia, \& Carreiras, 2016b, for extensive discussion).

As seen, nowadays the existence of a real bilingual advantage at the non-linguistic level of cognitive control is under debate, and the evidence in its support has been shown to be inconsistent (see Paap et al., 2015, among many others). This issue has drawn the attention of many researchers, and there is current convergence in highlighting the need for more longitudinal studies, including training studies, as well as more theory-driven approaches to investigate the potential effects of bilingualism on different forms or components of executive functioning at behavioral and neural levels (de Bruin \& Della Sala, 2015; GarcíaPentón et al., 2016a, 2016b; Li \& Grant, 2015; Paap, 2015). In the current study we will address this issue by exploring the manner in which the acquisition of a language in the elderly shapes monolingual seniors' switching abilities by comparing their performance before and after the linguistic training with that of a group of matched monolingual seniors that have not received any formal linguistic training in a new language. To do so, we focused on a classic task-switching paradigm (i.e., the colour-shape switching task).

One of the most frequently used paradigms to explore the potential advantages bilingualism may yield is the task-switching paradigm, and more specifically the colourshape switching task (for an example of the color-shape switching paradigm see Rubin and 
Meiran, 2005; see also Prior \& MacWhinney, 2010) ${ }^{1}$. In this task colourful geometric figures are presented to participants who are asked to respond either according to the colour or to the shape criterion of the figure. This task evaluates, primarily, the shifting ability between different mental sets (Miyake et al., 2000), providing a quantitative measure of the switching cost. While the switching cost is a relatively neat measure of shifting abilities, it should be also acknowledged that this index also reflects the ability to inhibit the previous trial rule, as inhibition and switching may be indivisible in this type of paradigms (see Paap \& Sawi, 2014). Switching cost gauges the level of interference that is created in participants' performance by the change from a non-switch trial (where the response criterion remains equal to the previous trial) to a switch trial (where the response criterion is different from the previous trial) in mixed-task blocks in which the response criteria are intermixed. The switching cost can be calculated by subtracting the mean reaction times (RTs) in the nonswitch trials from the mean RTs in the switch trials, as well as by calculating the difference on the error rates between switch trials and non-switch trials. In his review, Monsell (2003) postulated that the source of the switch cost could be in the so-called "task-set reconfiguration", a process where an adjustment of the criteria is done while the rules of the previous task are inhibited and the demands of the new one activated.

The relationship between bilingualism and switching skills stems from the constant need of bilinguals for switching from one language to another while suppressing the nonrelevant language as a function of the linguistic demands imposed by each context (e.g., Abutalebi \& Green, 2007; Bialystok \& Craik, 2010). In contrast to other measures of 1

In the current study we solely focused on the colour-shape switching paradigm, and for simplicity's sake we avoided lengthy discussion of other paradigms that have also been used to explore the broad concept of "cognitive flexibility", such as the Wisconsin Card Sorting Test -WCST- (Grant \& Berg, 1948; see Yudes, Macizo, \& Bajo, 2011, for an implementation with different groups of bilinguals and monolinguals). Even if the WCST has been taken as a proxy to some aspects of executive functioning (see Miyake et al., 2000), there are also clear-cut limitations imposed by this paradigm in terms of experimental outcomes (e.g., lack of RTs, impossibility to compute switching costs). 
different forms of executive functioning such as those related to inhibitory control, which has been more extensively studied in bilinguals (see Duñabeitia et al., 2014, for review), measures of switching skills have been commonly taken as a proxy for a broader spectrum of processes, given that switching costs are a reflection of the ability to switch between mental sets but also of the ability to inhibit the active rule from the previous trial (see Paap \& Sawi, 2014).

Among others, Prior and MacWhinney (2010), Garbin et al. (2010) and Prior and Gollan (2011) used a colour-shape switching paradigm to test how bilingualism could impact switching skills, and the results of these studies offer a somewhat inconclusive picture. The two first studies (Garbin et al., 2010; Prior \& MacWhinney; 2010) presented results in support of the bilingual advantage hypothesis in non-linguistic switching abilities. While Prior and MacWhinney (2010) reported significantly smaller switching costs in bilinguals than in monolinguals in terms of RTs (i.e., shorter response latencies when moving from a non-switch trial to a switch-trial), the behavioral data reported by Garbin et al. (2010) in their study using a modified version of this task showed smaller switching costs for bilinguals than for monolinguals only in terms of accuracy. In contrast, the study by Prior and Gollan (2011) added a new variable to the equation: the frequency of language switching in daily life. They tested a group of highly switching bilinguals, a group of low-switching bilinguals and a group of monolinguals, and the results demonstrated the importance of language use for the emergence of a significant bilingual advantage. Highly switching bilinguals exhibited smaller switching costs in the switching task than the other two groups, while low-switching bilinguals and monolinguals did not differ in their performance. However, Paap and Greenberg (2013) showed no difference in switching skills between bilinguals and monolinguals as a function of the frequency of language-switching, and other studies also testing young adults have revealed no differences between groups in the magnitude of the 
switch costs, providing evidence against the notion of a bilingual switching advantage (see Hernández, Martin, Barcelo, \& Costa, 2013; Paap and Sawi, 2014; Mor, Yitzhaki-Amsalem, and Prior, 2015).

Interestingly, the studies mentioned above investigated the presence of a bilingual advantage in switching skills in young adults who were, in most cases, early bilinguals who had acquired their L2 during childhood. In an attempt to explore if switching skills would differ in other age groups, more recently, de Bruin et al. (2015) investigated Gaelic-English active and inactive bilingual seniors as well as control monolingual seniors. They showed a significant RT difference (i.e., a reduced switching cost) only for active bilinguals, and not for inactive bilinguals as compared to monolinguals. However, when proportional switching costs were calculated in order to reduce possible baseline differences, de Bruin et al. showed that the three groups did not differ in terms of their switching skills. Hence, the possible impact of bilingualism in the elders' switching skills is not entirely clear, but the scarce evidence at this regard suggests that lifelong bilingual seniors and monolinguals do not differ significantly in their ability to switch between mental sets and to inhibit the preponderant response criterion from the preceding trial. Here we explored whether this is also the case for seniors who have been monolingual until adulthood, and who have undergone a linguistic training to acquire a second language in the old age. Longitudinal studies seem highly appropriated to shed light on the issue of the so-called bilingual advantage at different levels of executive functioning (see de Bruin \& Della Sala, 2015; García-Pentón et al., 2016a, 2016b; Paap, 2015). More specifically, training studies based on the acquisition of a second language are essential to understand the causality and interaction between bilingualism and the enhancement of executive functioning (see Duñabeitia \& Carreiras, 2015).

The very few longitudinal studies exploring the impact of L2 learning in domaingeneral cognitive abilities have mainly been conducted in young adults, and they have been 
oriented to studying the link between language and memory tasks (e.g., Grant, Fang, \& Li, 2015; Ljungberg et al., 2013; Yang, Gates, Molenaar, \& Li, 2015) or between musical training, bilingualism and executive functioning (see Moradzadeh, Blumenthal, \& Wiseheart, 2014). Interestingly, Sullivan et al. (2014) investigated the neural and behavioral effects of L2 acquisition in executive control in a group of early-stage young trainee adults who were enrolled in an introductory Spanish course. Their results showed significant electrophysiological changes (larger P3 amplitudes in a go/no-go task and smaller P600 amplitudes in a judgment task), and these data were interpreted as indicative of enhanced executive control, even though no behavioral differences between the experimental group and the control group were found. While none of these studies have tested neither older adults nor switching skills, several other longitudinal training studies have suggested that different forms of specific instruction or practice can improve seniors' switching abilities. Training studies exploring the impact of programs developing older adults' motor and physical activity, such as contemporary dance (e.g., Coubard et al., 2011) or aerobic exercise (e.g., Masley, Roetzheim, \& Gualtieri, 2009), have demonstrated the positive impact of these activities in switching skills. In parallel, the body of evidence supporting the positive effects of cognitive and physical trainings on neurodegenerative diseases and age-related cognitive decline is growing at an exponential pace (e.g., Voss et al., 2010; see Badimis et al., 2014, for a review). However, to date no study has directly explored the early effects derived from lately acquired bilingualism through explicit L2 training on specific aspects of executive functioning in the elderly, and the present study was aimed at filling this gap.

Here, we investigated whether second language (L2) training could result in an improvement on non-linguistic switching abilities in the old age, when the decline in executive functioning is more evident (see Cepeda, Kramer, \& Gonzalez de Sather, 2001), and when the magnitude of the switching costs in non-linguistic task-switching paradigms 
tends to increase (see Gold et al., 2010; Kramer et al., 1999). Considering the age-related decline in executive control, it is worth investigating the (neuro-)protective nature of linguistic training. Taking into consideration that some kinds of training have resulted effective to induce positive changes in age-related shifting ability decline and in light of a possible existence of a bilingual advantage in executive control, it would make sense to propose L2 learning as a type of training that could ameliorate the effects of ageing in the executive functions. This is especially important as it would be of great relevance to find similar neuroprotective effects of acquiring an L2 late in life to those reported in elderly lifelong bilinguals (Bialystok et al., 2014; Bialystok et al., 2007).

The present study aimed at exploring the effects of second language learning in the old age in the ability to shift between mental sets. To do so, we tested longitudinally the development of non-linguistic switching skills in a group of Spanish monolinguals over 60 years of age who attended Basque language classes for a whole academic year. In parallel, a group of Spanish-speaking monolingual active seniors who did not attend to any languagelearning course was also tested twice for control purposes. A colour-shape switching task was used as a measure of switching ability. We used a cued task-switching paradigm to isolate task switching ability from other cognitive abilities that may be involved in non-cued tasks, such as reasoning or inference-making. The pre-test and post-test data collection design allowed us to monitor for cognitive control changes as a function of language learning, exploring whether a linguistic training based on the acquisition of a second language in the elderly improves switching ability by reducing switching costs. Given the contradictory outcomes of preceding studies on the bilingual advantage in executive control, it is not clear whether the L2 learning in the elderly could either have a positive effect on task switching performance by enhancing the shifting ability of seniors, as suggested by results in line with the bilingual advantage, or as recent studies suggest, there would not be transfer effects from 
language training to non-verbal task-switching. Hence, the current longitudinal study with an experimental group of senior participants attending a language-learning course will be of help to ascertain whether monolingual elders' switching abilities could be improved by teaching them a new language.

\section{METHODS}

\subsection{Participants}

Two groups of right-handed healthy seniors were recruited for the current study. They all had normal or corrected-to-normal vision and gave informed consent prior to any research or educational action. The experimental group consisted of 26 Spanish monolingual (12 females; mean age $=67.42$; age range $=60-80$ ) that had no previous experience learning a second language. All participants had the Spanish nationality and were living in the Basque Country at the time of being tested, and except for a single individual, all of them were retired. The global cognitive state was assessed by the Spanish version of the MMSE (Lobo et al., 1979) (mean score $=28.38$; range 24-30) and 24 out of the 26 participants had completed the compulsory secondary school, obtaining the Secondary School Certificate. The mean age at which these participants quitted formal education was 15.30 years (standard deviation $=3.43$ ). None of the participants in the experimental group had any other native or second language different from Spanish as attested by a linguistic questionnaire that they completed in an initial screening session with the experimenters.

The control group consisted of 17 Spanish monolinguals from the same autonomous community from a similar socioeconomic background ( 9 females; mean age $=69.18$; age range $=60-78)$. These participants were all native Spanish speakers with no knowledge of any 
other language and were not enrolled in any language-learning course. 12 out of the 17 participants had obtained the Secondary School Certificate, and also except for one person, all were retired. The mean age at which participants in the control group quitted formal education was 16.65 years (standard deviation $=7.11$ ). Furthermore, all controls participants scored $\geq 24 / 30$ on the MMSE, thus as in the case of the experimental group had no signs of pathological cognitive deficits (MMSE mean score= 28.53; range= 24-30). The age of the participants, their global cognitive state as measured by the MMSE, and the age at which they quitted formal schooling did not statistically differ between the groups (all ps>.28) ${ }^{2}$.

The participants in the experimental group took Basque language lessons for a whole academic year, meaning that they attended a Basque course for 8 months, starting in October and finishing in June. The educational project was managed by a Center of Continuing Education for Adults under the direction of the Department of Education, Linguistic Policy and Culture of the Basque Government, and native Basque-Spanish bilingual professional language trainers who were specialized in adult teaching carried out all the pedagogical actions. The participants attended to Basque classes in small groups of maximum 10 participants per class for a total amount of 330 minutes of training per week, distributed in three different sessions in workdays (two sessions of 2 hours and one session of 1.5 hours). For their part, participants in the control group, despite being active community-dwelling individuals, did not undergo any kind of training during the 8 month interval between the pretest and the post-test, therefore forming a passive control group.

2

While the neuropsychological assessment suggested that none of the participants had signs of pathological cognitive deficits, we acknowledge that the use of additional scales of cognitive deterioration would have been desired. Nonetheless, it is important to mention that the number of participants scoring below 27 in the MMSE is markedly low in both groups, suggesting a good cognitive status of the participants. In the control group only 2 participants obtained a score of 24 , and just 1 got 26 . In the experimental group, only 1 got 24 and 1 got 26 . This solely represents a subsample of less than $12 \%$ of the general sample. 


\subsection{Materials and Procedure}

Stimuli consisted of a series of squares $(3 \mathrm{~cm}$ each side) and circles $(3 \mathrm{~cm}$ radius) that were displayed in either red or blue color in the center of the screen. The cues indicating the sorting criteria were the words "COLOR" and "FORMA" (the Spanish for color and shape), and these cues appeared $3 \mathrm{~cm}$ below each target figure. The experiment included a total of 80 trials that ensured a balanced presentation of all item combinations (red square, blue square, red circle and blue circle). The experiment comprised 48 critical trials, split in 24 switch trials and 24 non-switch trials. 32 filler trials, that were exactly the same to non-switch trials were also included to reduce the probability of a switch, in line with preceding studies suggesting that an increase in the proportion of deviant trials may yield a reduction of the observed differences (cf. Costa, Hernández, Costa-Faidella, \& Sebastián-Gallés, 2009; for a similar procedure in language-switching tasks, see among many others, Costa \& Santesteban, 2004; Meuter \& Allport, 1999). As the features of filler trials and non-switch trial were identical, same results in both types of trials would also prove the consistency of the findings. The experimental list was pseudo-randomized in line with classic mixed-blocks switching designs. None of the critical experimental non-switch trials occurred after a switch trial.

Every trial started with a fixation cross presented in the centre of the screen for 350 ms, immediately followed by the simultaneous presentation of the target stimulus and the cue until a response was given, or for a maximum of $5000 \mathrm{~ms}$. Participants in the experimental and control groups were asked to complete twice a switching task on a Macintosh computer with a 17-inch color monitor using Experiment Builder ${ }^{\circledR}$ (S-R Research, Ontario, Canada) for stimuli presentation and data collection. The first data collection was carried out at the end of September with the experimental group, before they had started the Basque lessons, and the second data collection was carried out in June, coinciding with the end of the 
academic course. The participants in the control group were also tested twice, with an 8months gap between the first and the second data collections. All participants were individually tested in the dependencies of the research center and of the educational agents by trained experimenters. They were seated approximately at a distance of $60 \mathrm{~cm}$ from the monitor that was located at the eye level, holding a response box connected to the computer. They were asked to make color or shape judgments by pressing one of two buttons in the response box as fast and as accurately as possible (i.e., the left button to respond blue-square and the right button to indicate red-circle). Participants were asked to have their thumbs placed in the target keys at all times. The test started with a series of practice trials that could be repeated as many times as requested by the participants to ensure a correct understanding of the task.

\section{RESULTS}

Prior to analyzing the results of the different phases and the different groups, we would want to stress that the participants who underwent the Basque learning training had effectively acquired basic knowledge. At the end of the first year of instruction, the trainees were asked to provide a numerical indicator of their self-perceived knowledge of the language and development in the training in a 0 -to-10 scale (10 being the maximum score corresponding to a perfect knowledge). The mean of this self-assessment was 5.54 (standard deviation $=1.45$ ). In parallel, the trainers (the specialized teachers) were asked to provide the official grade in a similar 0-to-10 marking system to each of the participants, and the mean of this evaluation was 5.65 (standard deviation $=1.38$ ), showing a high degree of consistency with the trainees' self-assessment $(\mathrm{r}=.73, \mathrm{p}<.001)$. In addition to this, we asked the participants to complete the Basque version of the LexTALE, a lexical test that is mainly 
intended to evaluate vocabulary knowledge as a proxy to language knowledge (see Lemhöfer \& Broersma, 2012). Results demonstrated that the participants were sensitive enough to the linguistic material to accurately distinguish between words and word-like pseudowords differently than what one would expect from chance-level responses (mean accuracy = $58.58 \%$; standard deviation $=5.74)$. Hence, we believe that these results can be taken as an indication of the relatively good linguistic performance of the experimental group, according to what one would have initially expected from an introductory course.

In order to assess switching ability, switching costs between switching and nonswitching trials were calculated measuring participants' accuracy (i.e., their error rates) and their reaction times (RTs) in milliseconds computed from the presentation of the target stimulus to the button press. Response latencies associated with correct responses were trimmed and cleaned from outliers, rejecting those RTs that fell beyond the limits established by the mean \pm 2.5 standard deviations for each participant in each experimental condition ( $2.63 \%$ of the data of the experimental group and $2.50 \%$ of the data of the control group). The remaining latency data were analyzed using ANOVAs following a $2 * 2 * 2$ design with the within-participant factors Phase (pre-test, post-test) and Type of Trial (switch, non-switch), and the between-participants factor Group (experimental, control). A 2*2 ANOVA with the factors Group and Phase was also carried out on the data corresponding to the filler trials in order to test the consistency of the results obtained in the preceding repeated measures ANOVAs, as filler trials were identical in essence to the non-switch trials. The analysis of the error rates (i.e., the percentages of errors) was carried out following the same exact designs than those used for the RT analysis. Mean RTs and error rates per Type of Trial, Phase and Group are presented in Table 1.

Table 1. Mean reaction times (in milliseconds) and mean error rates (in percentages of errors) per condition, group and phase. Standard deviations are provided in parentheses. The Switch Costs result from subtracting the Switch and the Non-Switch trials. 


\begin{tabular}{|c|c|c|c|c|}
\hline & \multicolumn{2}{|c|}{ EXPERIMENTAL TRIALS } & \multirow[b]{2}{*}{$\begin{array}{c}\text { SWITCH } \\
\text { COST }\end{array}$} & \multirow[b]{2}{*}{ FILLER TRIALS } \\
\hline & SWITCH TRIALS & $\begin{array}{c}\text { NON-SWITCH } \\
\text { TRIALS }\end{array}$ & & \\
\hline \multicolumn{5}{|c|}{ Experimental Group } \\
\hline \multicolumn{5}{|l|}{ Pre-Test } \\
\hline Reaction Times & $1510(512)$ & $1301(388)$ & 209 & $1355(338)$ \\
\hline Error Rates & $20.35(14.74)$ & $20.03(18.22)$ & 0.32 & $19.95(16.75)$ \\
\hline \multicolumn{5}{|l|}{ Post-Test } \\
\hline Reaction Times & $1381(521)$ & $1144(398)$ & 237 & $1217(424)$ \\
\hline Error Rates & $20.99(22.19)$ & $20.03(21.28)$ & 0.96 & $21.39(21.68)$ \\
\hline \multicolumn{5}{|l|}{ Control Group } \\
\hline \multicolumn{5}{|l|}{ Pre-Test } \\
\hline Reaction Times & $1766(601)$ & $1497(505)$ & 269 & $1589(554)$ \\
\hline Error Rates & $26.23(22.48)$ & $21.81(17.83)$ & 4.42 & $22.43(17.79)$ \\
\hline \multicolumn{5}{|l|}{ Post-Test } \\
\hline Reaction Times & $1697(641)$ & $1431(483)$ & 266 & $1561(574)$ \\
\hline Error Rates & $19.36(21.75)$ & $18.63(18.70)$ & 0.73 & $15.81(16.81)$ \\
\hline
\end{tabular}

\subsection{Reaction Times (RTs)}

ANOVAs on the RTs associated with the switch and non-switch trials showed a main effect of Type of Trial $[F(1,41)=55.69, p<.001]$, demonstrating that overall, switch trials were responded to significantly more slowly than non-switch trials. The main effect of Phase was not significant $[F(1,41)=1.86, p=.18]$, suggesting that $R T$ s did not markedly differ between the pre- and the post-test. The effect of Group was significant $[F(1,41)=4.22, p<.05]$, showing that the experimental group took significantly shorter than the control group to respond to all types of trials (see Table 1). Importantly, none of the two- or three-way interactions resulted significant [all $\mathrm{Fs}<1$ and $\mathrm{ps}>$.49], demonstrating that the linguistic training did not have any specific impact in the overall RTs of the experimental group, or in the magnitude of their switch costs, as compared to the control group.

The ANOVA on the RTs associated with the filler trials was fully consistent with the results described above, showing a significant effect of Group $[F(1,41)=5.43, p<.03]$ that demonstrated that the participants in the experimental group were overall faster than the 
participants in the control group. However, this Group-based difference did not vary as a function of the Phase, given the lack of an interaction between the two factors $[\mathrm{F}<1$ and $\mathrm{p}>$.45]. The main effect of Phase was not significant either $[\mathrm{F}<1.3$ and $\mathrm{p}>.26]$.

Finally, a Bayesian Null Hypothesis Testing was also carried out on the switch costs within and between groups, and the Bayes Factor $\left(\mathrm{BF}_{01}\right)$ was computed (see Rouder et al., 2009). When comparing the switch cost effects of the experimental and control groups in the pre-test by means of a Bayesian independent-samples t-test (Cauchy prior width $=0.707)$, the results showed that the acceptance of the null hypothesis was 2.80 times more probable than the alternative. Similarly, a parallel analysis on the switch cost effects obtained in the posttest demonstrated that the null hypothesis was 3.12 times more probable than the alternative. When the switching costs in the pre-test and post-test were compared in a series of Bayesian paired-samples t-tests for each group separately, similar results were also obtained: the $\mathrm{BF}_{01}$ was of 4.46 for the experimental group, and of 4.01 for the control group, demonstrating that in both cases the acceptance of the null hypothesis should be favored.

Figure 1. Mean Switch Costs in milliseconds per group (Experimental Group in white, Control Group in black) and phase (pre-test and post-test). Error bars represent 95\% confidence intervals. The Switch Costs result from subtracting the RTs in the Switch and the Non-Switch conditions.

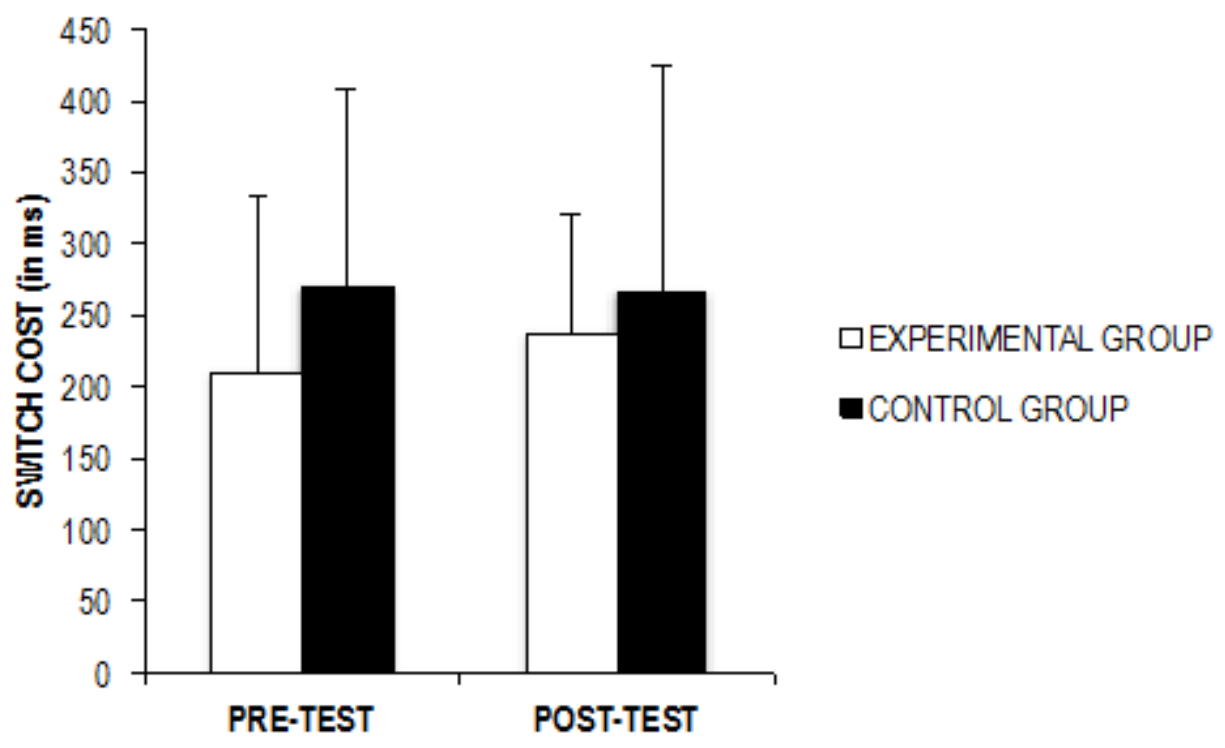




\subsection{Error Rates}

The ANOVA on the percentages of errors in the switch and non-switch trials did not show any significant main effect or interaction [all $\mathrm{Fs}<2.63$ and $\mathrm{ps}>.10$ ].

Similarly, the ANOVA on the error rates in the filler trials failed at showing any significant effect or interaction [Fs $<1.58$ and $\mathrm{ps}>.21]$.

\section{DISCUSSION}

The present study aimed at testing the effects of L2 training on switching ability in the old age. To do so, a group of Spanish elderly monolinguals were tested on a switching task prior to the start of a Basque language-learning program and subsequently, once the program finished at the end of the academic year, 8 months later. In parallel, a similar group of Spanish elderly monolinguals that did not complete any language-learning course was also tested for control purposes. Overall results showed that participants' switching ability as measured by the switching cost in a colour-shape switching task did not benefit from learning a new language, as switch costs remained relatively immutable in the two groups and in the two test moments.

The finding of a negligible reduction in switching costs as a consequence of the acquisition of a new language goes against a corpus of evidence headed by the studies by Prior and MacWhinney (2010), Garbin et al. (2010), or Prior \& Gollan (2011), among others, showing significantly smaller switch costs (or no switch costs at all) in bilingual samples' performance in the task switching paradigm as compared to the performance of their 
monolingual peers. In contrast, the current study adds to a growing body of literature failing to replicate bilinguals' enhanced switching abilities as compared to monolinguals (see Paap, Johnson, \& Sawi, 2015, for a compelling review). Interestingly, the current findings coincide to a great extent with those recently reported by de Bruin, Bak and Della Sala (2015), who demonstrated the absence of the so-called bilingual advantage in cognitive control in elderly bilinguals when measuring their switching abilities. In line with the set of studies demonstrating the somewhat weak link between the enhancement of executive functioning and bilingualism in the elderly (see Antón et al., 2016, for a comprehensive review), De Bruin and colleagues tested the effect of lifelong bilingualism on executive control in older active bilinguals, inactive bilinguals and monolinguals, trying to replicate the bilingual advantage in task-switching paradigms. Results of proportional switch costs and RTs did not show any specific advantage of bilingual seniors as compared to monolingual controls, casting doubts on the already hazy construct of the bilingual advantage (see also Antón et al., 2016; Duñabeitia et al., 2014; Paap, Johnson, \& Sawi, 2015, 2016). In this sense, it is worth noting that other recent findings in line with those reported by de Bruin et al. (2015) also question the notion of bilingual advantage in mechanisms related to executive control, showing that the magnitudes of the switch costs are not reduced in bilingual samples as compared to their monolingual counterparts (see Hernández et al., 2013; Paap \& Greenberg, 2013; Paap \& Sawi, 2014).

As highlighted by Paap and Sawi (2015; see de Bruin, Treccani, \& Della Sala, 2015, for a different set of arguments), many of the published studies reporting a bilingual advantage suffer from critical limitations, the main confounding constraints being methodological in essence, and mostly related to the difficulty to correctly match two groups (monolinguals and bilinguals) for the factors that could boost the appearance of a difference without being necessarily related to the determining between-groups factor at test (i.e., 
bilingualism). Sharing nearly all the concerns initially raised by Paap and Sawi, in their comment Duñabeitia and Carreiras $(2015$, p.372) recently hypothesized that "a different scenario may arose for bilinguals who have acquired a second language late in life" (see also Antoniou, Gunasekera, \& Wong, 2013). Crucially, here we tested this hypothesis while avoiding the concerns about between-groups matching through the use of a prospective cohort design following individuals without any knowledge of an L2 through a year of formal tuition in a new language. Thus, the current results stem from a longitudinal study exploring the potential impact of language learning in the elderly in the improvement of certain mechanisms related to executive functions, and specifically to switching ability. In this longitudinal training study, results do not speak in favor of a cognitive reconfiguration that leads to the enhancement of switching skills based on the late acquisition of a second language. In contrast, they speak for the relative independence of language learning processes and the improvement of switching skills in the elderly.

In their recent extensive review, Paap, Johnson and Sawi (2016) pointed out the direction of causality as one of the main problems of the-so called bilingual advantage framework, questioning that the potential differences found in executive control between monolingual and bilingual groups may not necessarily be due to the knowledge or use of more than one language. More importantly, even if one assumes the existence of a causal relationship between bilingualism and higher executive functions, the direction of the causality could be difficult to disentangle, as it is also plausible that bilinguals could master two languages just because of their inherently enhanced executive control. The literature on the so-called bilingual advantage has been mainly focused on cross-sectional studies, making the relationship of the causal direction difficult to verify. However, longitudinal designs could serve to obtain clearer outcomes on this causality issue (Grant, Fang, \& Li, 2015; Ljungberg et al., 2013; Moradzadeh, Blumenthal, \& Wiseheart, 2014; Yang, Gates, 
Molenaar, \& Li, 2015). Along these lines, we strongly believe that longitudinal studies can be the key that would definitely tip the scales in one direction or another for live debates on the existence of between-groups differences in the debate of the bilingual advantage (see Duñabeitia \& Carreiras, 2015; see also Paap et al., 2015). In fact, the importance of longitudinal studies has been recently highlighted in parallel debates on the potentially beneficial effects of bilingualism as a source of neuropsychological protection. While some cross-sectional studies have reported positive findings in favor of bilingual seniors, suggesting that bilingualism may delay the onset of dementia (see Albán-González \& OrtegaCampoverde, 2014; Bialystok, Craik, \& Freedman, 2007), others have not obtained these same outcomes (see Chertkow et al., 2010). However, longitudinal studies at this regard have provided a less ambiguous picture, coinciding in showing no delay in the onset of the symptoms as a function of bilingualism (e.g., Crane et al., 2009; Lawton, Gasquoine, \& Weimer, 2015; Sanders et al., 2012; Zahodne et al., 2014).

Nevertheless, some clear-cut limitations of the current study should also be acknowledged. Ideally, studies on cognitive training programs include active control groups as well as passive control groups to be able to test the efficacy of the training and also to dissociate the effects of different cognitively demanding types of training (see Coubard et al., 2011), and in the current study we did not have the chance to include an active control group. However, we sincerely believe that this is an issue that does not diminish the impact of the current findings given that we did not find positive effects of the training on the switching abilities of the participants immersed in the L2 acquisition program. Hence, the inclusion of additional control groups would not necessarily yield a methodological improvement in a scenario in which participants' non-linguistic behavior and performance did not change as a consequence of the intervention. One possible limitation concerns the assignment of the participants to the groups, as it was not done randomly, given that participants in the 
experimental group had to voluntarily sign for the Basque course and were selected after a careful examination of their language background. However, and due to obvious reasons, this is a common practice in this type of studies (see also Yang, Gates, Molenaar, \& Li, 2015). Nonetheless, and despite the existence of possible uncontrolled cognitive differences between the groups already at pre-test that could have modulated the results, we believe that the inclusion of a control group represents a clear-cut improvement with regard to preceding longitudinal training studies exploring the impact of L2 acquisition (see Grant, Fang, \& Li, 2015). Also, we circumscribed the current study to non-verbal switching abilities as a proxy to the construct of executive control. As already discussed by several authors, executive control and bilinguals' language control do exhibit qualitative differences in the set of mechanisms and cognitive structures they recruit (e.g., Calabria, Hernández, Branzi, \& Costa, 2012). Hence, establishing a direct link between a specific training in language control or in language acquisition and a consequent improvement of non-linguistic control may not be an easy endeavor, especially when participants' knowledge of the newly acquired L2 is at its basic level. However it should be noted that despite the fact that participants' Basque language knowledge was narrow after the introductory training, they were able to use it beyond the classroom, and so they did. This is possible due to Basque Country's sociolinguistic context, in which a great part of the population speaks Basque and Spanish in everyday life. Of the nearly 2 million population of the Basque Country, the percentage of Spanish-Basque bilinguals is roughly $50 \%$, while the other $50 \%$ of the population is Spanish monolingual. Nowadays, the percentage of bilinguals in the age range between 16 and 25 is around $60 \%$, and this percentage is expected to increase in following years, considering that almost $85 \%$ of Basque children are immersed in a bilingual learning context according to the latest indicators of the Basque Statistics Institute (EUSTAT). Hence, by means of providing our Spanish-speaking seniors with elementary Basque, we have provided them with a 
language that they can and do use out of academic contexts, in their social interactions among them, and especially with their younger relatives, who show a preference for using Basque. For this reason, and differently from other training studies in which participants learn a language which is not present in the context (e.g., a foreign language), our participants in the experimental group can be considered as active neo-bilinguals immersed in a high-switching context given their sociolinguistic reality (see Paap \& Greenberg, 2013; Prior \& Gollan, 2011).

An issue that is still a matter of controversy and that cannot be directly addressed in studies with neo-bilinguals is the potential effect(s) of lifelong bilingualism on domaingeneral cognitive control. It has been argued that the use of more than one language could lead to an improvement on executive functions and to a neural reconfiguration if this bilingual linguistic experience is "sustained, intense, and all-encompassing" (Bialystok, 2016, p. 6). Hence, the effects of long-term bilingual experience and short-term L2 training may not be comparable, and it could be considered that only lifelong practice in switching between languages yields an enhancement of non-verbal switching abilities that can be captured with classic behavioral measures (e.g., Prior \& MacWhinney, 2010; Garbin et al., 2010; Prior \& Gollan, 2011). In fact, the study with Sullivan et al. (2014) investigating the effects of introductory L2 acquisition in young adults demonstrated positive effects of a 6month language training in executive functioning only at an electrophysiological level, while no signs of such enhancement were found at the behavioral level. Thus, the lack of positive results observed in the current study with neo-bilinguals may not result surprising, and we cannot rule out the possibility that future studies after longer training periods could underscore potential differences as a consequence of L2 acquisition. Nonetheless, it is also worth considering the possibility that the effects of bilingualism on different forms of executive functions are negligible and unreliable (see Gasquoine, in press, for a review; see 
also de Bruin et al., 2015; Paap et al., 2015). It has been shown that the so-called bilingual advantage sometimes reported in non-linguistic domains is a finding circumscribed to specific and unclear situations, which does not extend to samples of lifelong bilingual seniors or to neo-bilingual seniors. The results recently obtained by Antón et al. (2016) point in this direction. They tested lifelong bilingual and monolingual seniors' executive functions using verbal and numerical Stroop paradigms in an attempt to explore whether lifetime bilingualism had an effect on domain-general cognitive abilities (cf. Duñabeitia et al., 2014). The results demonstrated a lack of differences between bilinguals and monolinguals, and when L2 proficiency was taken into account, no correlation between the mastery of a second language and non-linguistic cognitive functions was found in the elderly.

It is unclear whether longer L2 training periods could give rise to behavioral differences in executive functions and whether bilingualism truly modulates domain-general cognitive functions in the elderly. Hence, additional research with ageing population is needed in order to shed light on these questions. In this sense, we would want to emphasize that the current study is the first known investigation testing the effects of L2 learning on non-linguistic switching abilities in the elderly, opening new doors to a better understanding of the link between learning a second language late in life and the ability to shift between mental sets. While the research line exploring the cognitive impact of language learning in the elderly is still in its infancy, we are confident that future longitudinal studies will provide compelling evidence on the cognitive impact of L2 acquisition in old age. 


\section{ACKNOWLEDGEMENTS}

This research has been partially funded by grants PSI2015-65689-P and SEV-20150490 from the Spanish Government, PI2015-1-27 from the Basque Government, ERC-AdG295362 grant from the European Research Council, the AThEME project funded by the European Union (grant number 613465), and by a research grant from the BBVA Foundation. The authors are grateful to Janire Akasuso (Mancomunidad de Servicios del Txorierri) for her kind support and help. 


\section{REFERENCES}

1. Abutalebi, J., \& Green, D. (2007). Bilingual language production: The neurocognition of language representation and control. Journal of neurolinguistics, 20(3), 242-275.

2. Albán-González, G., \& Ortega-Campoverde, T. (2014). Relationship between bilingualism and Alzheimer's. Suma de Negocios, 5(11), 126-133.

3. Antón, E., Duñabeitia, J. A., Estévez, A., Hernández, J. A., Castillo, A., Fuentes, L. J., ... Carreiras, M. (2014). Is there a bilingual advantage in the ANT task? Evidence from children. Front Psychol, 398(5), 1-12.

4. Antón, E., Fernández García, Y., Carreiras, M., \& Duñabeitia, J.A. (2016). Does bilingualism shape inhibitory control in the elderly? Journal of Memory and Language, 90, 147-160.

5. Antoniou, M., Gunasekera, G. M., \& Wong, P. C. (2013). Foreign language training as cognitive therapy for age-related cognitive decline: a hypothesis for future research. Neuroscience \& Biobehavioral Reviews, 37(10), 2689-2698.

6. Bak, T. H., Nissan, J. J., Allerhand, M. M., \& Deary, I. J. (2014). Does bilingualism influence cognitive aging? Annals of neurology, 75(6), 959-963.

7. Bamidis, P., Vivas, A., Styliadis, C., Frantzidis, C., Klados, M., Schlee, W., ... Papageorgiou, S. (2014). A review of physical and cognitive interventions in aging. Neuroscience \& Biobehavioral Reviews, 44, 206-220.

8. Bialystok, E. (2016). Aging and bilingualism. Why does it matter? Linguistic Approaches to Bilingualism, 6, 1-8.

9. Bialystok, E., Abutalebi, J., Bak, T. H., Burke, D. M., \& Kroll, J. F. (2016). Aging in two languages: Implications for public health. Ageing Research Reviews, 27, 56-60. 
10. Bialystok, E., \& Craik, F.I.M. (2010). Cognitive and linguistic processing in the bilingual mind. Current directions in psychological science, 19(1), 19-23.

11. Bialystok, E., Craik, F. I. M., Binns, M.A., Ossher, L. \& Freedman, M. (2014). Bilingualism effect on the age of onset and progression of MCI and AD: Evidence from executive function tests. Neuropsychology, 2, 290-304.

12. Bialystok, E., Craik, F. I. M., \& Freedman, M. (2007). Bilingualism as a protection against the onset of symptoms of dementia. Neuropsychologia, 45(2), 459-464.

13. Bialystok, E., Craik, F.I.M., Klein, R., \& Viswanathan, M. (2004). Bilingualism, aging and cognitive control: Evidence from the Simon task. Psychology and Aging, 19, 290-303.

14. Bialystok, E., Craik, F. I.M., \& Luk, G. (2012). Bilingualism: consequences for mind and brain. Trends in cognitive sciences, 16(4), 240-250.

15. Bialystok, E., Craik, F.I.M., \& Luk, G. (2008). Cognitive control and lexical access in younger and older bilinguals. Journal of Experimental Psychology: Learning, memory, and cognition, 34(4), 859.

16. Calabria, M., Hernández, M., Branzi, F, M., \& Costa, A. (2012). Qualitative differences between bilingual advantage language control and executive control: Evidence from task-switching. Frontiers in Psychology, 2, 399.

17. Cepeda, N. J., Kramer, A. F., \& Gonzalez de Sather, J. (2001). Changes in executive control across the life span: examination of task-switching performance. Developmental psychology, 37(5), 715.

18. Chertkow, H., Whitehead, V., Phillips, N., Wolfson, C., Atherton, J., \& Bergman, H. (2010). Multilingualism (but not always bilingualism) delays the onset of Alzheimer disease: evidence from a bilingual community. Alzheimer Disease \& Associated 
Disorders, 24(2), 118-125.

19. Costa, A., Hernández, M., Costa-Faidella, J., \& Sebastián-Gallés, N. (2009). On the bilingual advantage in conflict processing: now you see it, now you don't. Cognition, $113(2), 135-149$.

20. Costa, A. \& Santesteban, M. (2004). Lexical access in bilingual speech production: Evidence from language switching in highly proficient bilinguals and L2 learners. Journal of Memory and Language, 50, 491-511.

21. Coubard, O. A., Duretz, S., Lefebvre, V., Lapalus, P., \& Ferrufino, L. (2011). Practice of contemporary dance improves cognitive flexibility in aging. Frontiers in aging neuroscience, 3(13), 1-12.

22. Crane, P. K., Gibbons, L. E., Arani, K., Nguyen, V., Rhoads, K., McCurry, S. M., ... \& White, L. (2009). Midlife use of written Japanese and protection from late life dementia. Epidemiology, 20(5), 766.

23. Crane, P. K., Gruhl, J. C., Erosheva, E. A., Gibbons, L. E., McCurry, S. M., Rhoads, K., . . . White, L. (2010). Use of spoken and written Japanese did not protect Japanese-American men from cognitive decline in late life. The journals of gerontology. Series B, Psychological sciences and social sciences, 65(6), 654-666.

24. de Bruin, A., Bak, T. H., \& Della Sala, S. (2015). Examining the effects of active versus inactive bilingualism on executive control in a carefully matched nonimmigrant sample. Journal of Memory and Language, 85, 15-26.

25. de Bruin, A., \& Della Sala, S. (2015). The importance of language use when studying the neuroanatomical basis of bilingualism. Language, Cognition and Neuroscience (ahead-of-print), 1-5.

26. de Bruin, A., Treccani, B., \& Della Sala, S. (2015). Cognitive Advantage in Bilingualism An Example of Publication Bias?. Psychological Science, 26(1), 99-107. 
27. Duñabeitia, J. A., \& Carreiras, M. (2015). The bilingual advantage: Acta est fabula. Cortex, 73, 371-372.

28. Duñabeitia, J. A., Hernández, J. A., Antón, E., Macizo, P., Estévez, A., Fuentes, L. J., \& Carreiras, M. (2014). The inhibitory advantage in bilingual children revisited: Myth or reality? Experimental psychology, 61(3), 234-251.

29. Eriksen, B. A., \& Eriksen, C. W. (1974). Effects of noise letters upon the identification of a target letter in a nonsearch task. Perception \& psychophysics, 16(1), 143-149.

30. Garbin, G., Sanjuan, C., Forn, C., Bustamante, J.C., Rodriguez-Pujadas, A., Belloch, V., Hernández, M., Costa, A., \& Ávila, C. (2010). Bridging language and attention: Brain basis of the impact of bilingualism on cognitive control. Neuroimage, 53, 12721278.

31. García-Pentón, L., Fernández García, Y., Costello, B., Duñabeitia, J. A., \& Carreiras, M. (2016a). "Hazy" or "jumbled"? Putting together the pieces of the bilingual puzzle. Language, Cognition and Neuroscience, 31(3), 353-360.

32. García-Pentón, L., Fernández García, Y., Costello, B., Duñabeitia, J. A., \& Carreiras, M. (2016b). The neuroanatomy of bilingualism: how to turn a hazy view into the full picture. Language, Cognition and Neuroscience, 31(3), 303-327.

33. Gasquoine, P. G. (in press). Effects of Bilingualism on Vocabulary, Executive Functions, Age of Dementia Onset, and Regional Brain Structure. Neuropsychology.

34. Gathercole, V.C., Thomas, E.M., Kennedy, I., Prys, C., Young, N., Viñas, G. N., \& Jones, L. (2014). Does language dominance affect cognitive performance in bilinguals? Lifespan evidence from preschoolers through older adults on card sorting, Simon and Metalinguistic tasks. Frontiers in Psychology, 5(11).

35. Gold, B.T., Kim, C., Johnson, N.F., Kryscio, R.J., \& Smith, C.D. (2013). Lifelong 
bilingualism maintains neural efficiency for cognitive control in aging. The Journal of Neuroscience, 33, 387-396.

36. Gold, B.T., Powell, D.K., Xuan, L., Jicha, G.A., \& Smith, C.D. (2010). Age-related slowing

of task-switching is associated with decreased integrity of frontoparietal white matter. Neurobiology of Aging, 31, 512-522.

37. Grant, D. A., \& Berg, E. A. (1948). A behavioral analysis of degree of reinforcement and ease of shifting to new responses in a Weigl-type card-sorting problem. Journal of Experimental Psychology, 38, 404-411.

38. Grant, A. M., Fang, S.-Y., \& Li, P. (2015). Second language lexical development and cognitive control: a longitudinal fMRI study. Brain and Language, 144, 35e47.

39. Hernández, M., Costa, A., Fuentes, L. J., Vivas, A. B., \& Sebastian-Galles, N. (2010). The impact of bilingualism on the executive control and orienting networks of attention. Bilingualism: Language and Cognition, 13(3), 315-325.

40. Hernández, M., Martin, C. D., Barceló, F., \& Costa, A. (2013). Where is the bilingual advantage in task-switching? Journal of Memory and Language, 69, 257-276.

41. Kramer, A. F., Hahn, S., \& Gopher, D. (1999). Task coordination in aging: explorations of executive control processes in the task-switching paradigm. Acta Psychologica, 101, 339-378.

42. Kroll, J. F., \& Bialystok, E. (2013). Understanding the Consequences of Bilingualism for Language Processing and Cognition. Journal of cognitive psychology, 25(5), 497514.

43. Lawton, D. M., Gasquoine, P. G., \& Weimer, A. A. (2015). Age of dementia diagnosis in community dwelling bilingual and monolingual Hispanic Americans. Cortex, 66, 141-145. 
44. Lemhöfer, K., \& Broersma, M. (2012). Introducing LexTALE: A quick and valid Lexical Test for Advanced Learners of English. Behavior Research Methods, 44, $325-$ 343.

45. Li, P., \& Grant, A. (2015). Identifying the causal link: Two approaches toward understanding the relationship between bilingualism and cognitive control. Cortex, 73, 358-360.

46. Ljungberg, J. K., Hansson, P., Andres, P., Josefsson, M., \& Nilsson, L.G. (2013). A longitudinal study of memory advantages in bilinguals. PLoS One, 8, e73029.

47. Lobo, A., Ezquerra, J., Gómez, F., Sala, J. y Seva, A. (1979) El mini-examen cognoscitivo. Un test sencillo y práctico para detectar alteraciones intelectuales en pacientes médicos. Actas Luso Españolas de Neurología y Psiquiatría, 7, 189-201.

48. Luk, G., Green, D. W., Abutalebi, J., \& Grady, C. (2011). Cognitive control for language switching in bilinguals: A quantitative meta-analysis of functional neuroimaging studies. Lang Cogn Process, 27(10), 1479-1488.

49. Masley, S., Roetzheim, R., \& Gualtieri, T. (2009). Aerobic exercise enhances cognitive flexibility. Journal of clinical psychology in medical settings, 16(2), 186193.

50. Meuter, R.F.I. \& Allport, A. (1999). Bilingual Language Switching in Naming: Asymmetrical Costs of Language Selection. Journal of Memory and Language, 40, $25-40$.

51. Miyake, A., \& Friedman, N. P. (2012). The nature and organization of individual differences in executive functions four general conclusions. Current directions in psychological science, 21(1), 8-14.

52. Miyake, A., Friedman, N.P., Emerson, M.J., Witzki, A.H. \& Howerter, A. (2000). The unity and diversity of executive functions and their contributions to complex 
“frontal lobe" tasks: A latent variable analysis. Cognitive Psychology, 41, 49-100.

53. Monsell, S. (2003). Task switching. Trends in Cognitive Sciences, 7, 134-140.

54. Mor, B., Yitzhaki-Amsalem, S. \& Prior, A. (2015). The joint effect of bilingualism and ADHD on executive functions. J Atten Disord. 19(6):527-41.

55. Moradzadeh, L., Blumenthal, G. \& Wiseheart, M. (2014). Musical training, bilingualism and executive function: a closer look to at task-switching and dual-task performance. Cognitive Science. 39 (5), 1-29.

56. Paap, K. R. (2015). The neuroanatomy of bilingualism: will winds of change lift the fog? Language, Cognition and Neuroscience (ahead-of-print), 1-4.

57. Paap, K. R. \& Greenberg, Z. I. (2013). There is no coherent evidence for a bilingual advantage in executive processing. Cognitive Psychology, 66, 232-258.

58. Paap, K. R., Johnson, H. A., \& Sawi, O. (2016). Should the Search for Bilingual Advantages in Executive Functioning Continue? Cortex, 74, 305-14.

59. Paap, K.R., Johnson, H. A. \& Sawi, O. (2015). Bilingual advantages in executive functioning either do not exist or are restricted to very specific and undetermined circumstances. Cortex, 69, 265-278.

60. Paap, K.R., \& Sawi, O. (2014). Bilingual advantages in executive functioning: problems in convergent validity, discriminant validity and the identification of the theoretical constructs. Frontiers in Psychology, 5, 962-977.

61. Pliatsikas, C., \& Luk, G. (2016). Executive control in bilinguals: a concise review on fMRI studies. Bilingualism: Language and Cognition, 1469-1841.

62. Prior, A., \& Gollan, T. H. (2011). Good language switchers are good task-switchers: Evidence from Spanish-English and Mandarin-English bilinguals. Journal of International Neuropsychological Society, 17, 682-691.

63. Prior, A., \& MacWhinney, B. (2010). A bilingual advantage in task switching. 
Bilingualism: Language and Cognition, 13, 253-262.

64. Rouder, J. N., Speckman, P. L., Sun, D., Morey, R. D., \& Iverson, G. (2009). Bayesian $\mathrm{t}$ tests for accepting and rejecting the null hypothesis. Psychonomic Bulletin \& Review, 16(2), 225-237.

65. Rubin, O., \& Meiran, N. (2005). On the origins of the task mixing cost in the cuing task-switching paradigm. Journal of Experimental Psychology. Learning, Memory, and Cognition, 31, 1477-1491.

66. Sanders, A. E., Hall, C. B., Katz, M. J., \& Lipton, R. B. (2012). Non-native language use and risk of incident dementia in the elderly. Journal of Alzheimer's Disease, 29(1), 99-108.

67. Simon, J. R., \& Rudell, A. P. (1967). Auditory SR compatibility: the effect of an irrelevant cue on information processing. Journal of applied psychology, 51(3), 300304.

68. Stroop, J. R. (1935). Studies of interference in serial verbal reactions. Journal of experimental psychology, 18(6), 643-662.

69. Sullivan, M.D., Janus, M., Sylvain, M., Astheimer, L. \& Bialystok, E. (2014). Early stage-second language learning improves executive control: Evidence from ERP. Brain \& Language, 139, 84-98.

70. Voss, M. W., Prakash, S. P., Erickson, K. I., Basak, C., Chaddock, L., Kim, J. S., Alves, H., Heo, S., Szabo, A. M., White, S. M., Wójcicki, T. R., Mailey, E. M., Gothe, N., Olson, E. A., McAuley, E., \& Kramer, A. F. (2010). Plasticity of brain networks in a randomized intervention trial of exercise training in older adults. Frontiers in Aging Neuroscience, 2, 32.

71. Wilson, R. S., Boyle, P. A., Yang, J., James, B. D., \& Bennett, D. A. (2015). Early life instruction in foreign language and music and incidence of mild cognitive 
impairment. Neuropsychology, 29(2), 292.

72. Yang, J., Gates, K. M., Molenaar, P., \& Li, P. (2015). Neural changes underlying successful second language word learning: an fMRI study. Journal of Neurolinguistics, 33, 29e49.

73. Yudes, C., Macizo, P., \& Bajo, T. (2011). The influence of expertise in simultaneous interpreting on non-verbal executive processes. Frontiers in Psychology, 2, 309-318.

74. Zahodne, L. B., Schofield, P. W., Farrell, M. T., Stern, Y., \& Manly, J. J. (2014). Bilingualism does not alter cognitive decline or dementia risk among Spanishspeaking immigrants. Neuropsychology, 28(2), 238-246. 